\title{
A modelagem (matemática) implícita nos processos criativos de uma arquiteta
}

\author{
Zulma Elizabete de Freitas Madruga ${ }^{1}$ \\ Universidade Federal do Recôncavo da Bahia (UFRB), Centro de Formação de Professores, \\ Amargosa, Bahia, Brasil
}

\section{Resumo}

Esta pesquisa tem como objetivo compreender os procedimentos de trabalho de uma arquiteta, analisando-os comparativamente com as etapas da modelagem (matemática). A colaboradora concedeu entrevista por meio de narrativas, que foram gravadas e posteriormente transcritas para análise. Trata-se de uma pesquisa qualitativa na qual foi utilizado como procedimento metodológico o mapeamento na pesquisa educacional, organizado em dois momentos: apreensão dos dados por meio das narrativas da colaboradora e significação dos dados, resultado da identificação, compreensão e interpretação desses dados. Os resultados mostraram que, embora essa profissional não assuma a utilização da modelagem em seus fazeres, esta se faz presente nos procedimentos utilizados pela profissional. A partir desse resultado, foi possível pensar em estratégias metodológicas passíveis de serem aplicada à Educação Básica.

Palavras-chave: Arquiteta; Modelagem (matemática); Narrativas.

\section{The modelling (mathematics) implied in the creative processes of an architect}

\begin{abstract}
This research aims to understand the work procedures of an architect, analyzing them comparatively with the stages of modelling (mathematics). The collaborator it granted interviews through narratives, which were recorded and later transcribed for analysis. It is a qualitative research in which the mapping in educational research was used as a methodological procedure, organized in two moments: apprehension of the data through the collaborator's narratives and meaning of that data, result of the identification, understanding and interpretation these dice. The results showed that, although this professional does not assume the use of modelling in her work, it is present in the procedures used by the professional. From this result, it is possible to think of methodological strategies that can be applied to Basic Education.
\end{abstract}

Keywords: Architect; Modelling (mathematics); Narratives.

Submetido em: 15/02/2021

Aceito em: 19/04/2021

Publicado em: 08/05/2021

\footnotetext{
${ }^{1}$ Doutora em Educação em Ciências e Matemática pela Pontifícia Universidade Católica do Rio Grande do Sul (PUCRS). Professora do Programa de Pós-Graduação em Educação em Ciências e Matemática da Universidade Estadual de Santa Cruz (UESC). Líder do Grupo de Estudos e Pesquisas em Tendências da Educação Matemática e Cultura (GEPTEMaC). Endereço para correspondência: Rua das Orquídeas, 61, Rodão, Amargosa, BA, CEP.45300-000. E-mail: betemadruga@ufrb.edu.br.
} 


\section{La modelación (matemáticas) implícita en los procesos creativos de una arquitecta}

\section{Resumen}

Este artículo tiene como objetivo comprender los procedimientos de trabajo de una arquitecta, analizándolos comparativamente con las etapas del modelación (matemáticas). La colaboradora concedió entrevistas a través de narrativas, que fueron grabadas y luego transcritas para su análisis. Se trata de una investigación cualitativa en la que se utilizó el mapeo en la investigación educativa como procedimiento metodológico, organizado en dos momentos: aprehensión de los datos a través de las narrativas de la colaboradora y significado de los datos, resultado de la identificación, comprensión y interpretación de estos datos. Los resultados mostraron que, mismo que esta profesional no asuma el uso del modelación en su trabajo, la miesma está presente en los procedimientos que utiliza la profesional. A partir de este resultado, fue posible pensar en estrategias metodológicas que pudieran aplicarse a la Educación Básica.

Palabras clave: Arquitecto; Modelación (matemáticas); Narrativas.

\section{Apresentação}

A arte e os processos criativos são constantes em vários ramos profissionais. Conforme Ostrower (2014), criar é conceber forma a algo novo, repleto de novas interpretações que se compõem na mente das pessoas, abarcando o relacionar, ordenar, configurar e significar. É dar existência, dar origem, gerar, inventar, produzir. A criação de algo acontece em todos os momentos, nas mais diversas profissões. A arte (atividade humana relacionada às manifestações de ordem estética) é expressa nas mais distintas profissões.

E na escola não deve ser diferente, os estudantes apresentam por vezes um potencial criativo que não é explorado pelos professores, de acordo com Madruga e Lima (2018, p. 201) “o desenvolvimento do senso criativo e a incitação para que o estudante expresse sua criatividade podem ser feitos desde os anos iniciais da Educação Básica”.

Madruga (2016) afirma que o senso criativo é inerente às pessoas e proveniente, principalmente, de seu patrimônio e contexto humano, social e cultural, e este necessita de estímulo, sendo que o mais indicado seria estimulá-lo enquanto estudante. E esse estímulo à criatividade é indicado nos documentos oficiais, como por exemplo na Base Nacional Comum Curricular - BNCC, a qual traz como competência geral da Educação Básica, entre outras:

Exercitar a curiosidade intelectual e recorrer à abordagem própria das ciências, incluindo a investigação, a reflexão, a análise crítica, a imaginação e a criatividade, para investigar causas, elaborar e testar hipóteses, formular e resolver problemas e criar soluções (inclusive tecnológicas) com base nos conhecimentos das diferentes áreas. (BRASIL, 2018, p. 9) 
Nesse sentido, é necessário reconhecer que a criatividade e o despertar da curiosidade podem ser desenvolvidos nos estudantes por meio da investigação, ainda de acordo com a BNCC “os estudantes devem desenvolver habilidades relativas aos processos de investigação, de construção de modelos e de resolução de problemas" (BRASIL, 2018, p. 519), em diversos contextos. Essa afirmação corrobora com a ideia de se utilizar na Educação Básica a Modelagem na Educação, definida por Biembengut (2016) como método de pesquisa, aplicado à educação, que consiste na construção de um modelo, seja ele matemático ou não. Pois esse método de ensino atende às indicações da $\mathrm{BNCC}$, ao estimular o estudante a construir modelos e resolver problemas, além de potencializar o desenvolvimento do senso criativo.

A BNCC reitera em diferentes trechos essa orientação para resolução de problemas e construção de modelos em diversos contextos. Esses 'contextos' são variáveis, e devem estar de acordo com a realidade social, econômica e cultural de cada escola e região. Nesse sentido, "o estudo de distintos processos criativos, por exemplo, poderá permitir ao estudante inteirarse de conceitos de diferentes áreas do conhecimento e, ao mesmo tempo, conhecer e valorar a cultura de cada grupo social” (MADRUGA; LIMA, 2018, p. 201).

Nas mais diversas profissões (contextos), permeiam a construção de modelos e a criatividade, elementos essenciais que devem estar constantemente presentes nas aulas de Matemática, por exemplo. Para isso, indica-se o uso da Modelagem na Educação, pois profissionais de diferentes ramos utilizam-se dos procedimentos de modelagem para realizar seus trabalhos, essa afirmação pode ser comprovada em diversas pesquisas publicadas, conforme explicitado a seguir.

Os processos de trabalho de uma modista, por exemplo, podem ser comparados com as etapas da modelagem, como afirma Madruga (2017b, p. 47), suas análises das narrativas da modista possibilitaram "identificar as três fases do processo de modelagem (matemática) utilizadas para solucionar ou compreender uma situação-problema ou um fenômeno". Pois esta profissional segue etapas como: solicitação de cliente; busca em lojas, revista, entre outros; imaginação e esboço do modelo em papel; confecção de molde - peça piloto; confecção da roupa; avaliação na pessoa e pela pessoa.

Uma designer de unha artísticas, no processo de desenhar em unhas de clientes, ou na produção de adesivos, é outra profissional que teve seus procedimentos comparados à Modelagem (matemática) e foram verificadas similaridades (MADRUGA; SCHELLER, 2019). Essa profissional percorre etapas como: solicitação de cliente ou escolha de desenho; busca por informações; elaboração de modelos em unhas postiças, na própria unha ou fotografias; criação dos desenhos ou adesivos; avaliação por parte da cliente. 
Outro artigo similar apresenta os procedimentos de dois pesquisadores: um de ciências humanas e outro de ciências exatas, comparando seus métodos para produção de artigos e revistas, com os processos de modelagem (MADRUGA, 2017a). Conforme resultados oriundos dos dados, esses pesquisadores, em suas produções acadêmicas utilizam os seguintes procedimentos: partem de uma ideia ou tema; levantam informações; selecionam material, diálogo entre os pares e primeiras sistematizações; escritas iniciais, compilação dos resultados; criação do produto (artigo ou livro); avaliação contínua pelo investigador e avaliação por parte de outros pesquisadores.

Estes artigos têm em comum o fato de verificarem semelhanças entre os processos criativos dos profissionais indicados e as etapas de modelagem (matemática) na educação, na perspectiva de Biembengut (2016). Estas publicações diferem deste artigo no que tange ao profissional, pois aqui, analisa-se o trabalho de uma arquiteta no processo de construção de projetos de edificações. Nesse sentido, este artigo tem como questão de pesquisa: Quais as similaridades entre o trabalho de uma arquiteta e os procedimentos de modelagem (matemática)? Para isso objetiva-se compreender os procedimentos de trabalho de uma arquiteta, analisando-os comparativamente com as etapas da modelagem (matemática). Assim, apresentam-se a seguir as bases teóricas que sustentam a pesquisa: processos criativos e modelagem (matemática) na educação, seguidos dos procedimentos metodológicos da pesquisa, seus resultados e discussões, e considerações finais.

\section{Processos Criativos e Modelagem na Educação}

Uma pessoa criativa resolve problemas, molda produtos ou proporciona a emersão de novas questões em determinado campo de uma forma inicialmente incomum, mas que posteriormente são aceitas em seu grupo cultural (GARDNER, 1999). Segundo o autor, seu "enfoque incide com a mesma intensidade sobre a resolução de problemas, a descoberta de problemas e a criação de produtos, tais como teorias científicas, obras de arte ou a fundação de instituições" (GARDNER, 1999, p.151).

Para Lubart (2007), a noção de processo criativo remete à sucessão de pensamentos e ações que resultam em criações originais e adaptadas. Ao basearem-se no gênero de evidência introspectiva, Lubart (2007) e Alencar (1993) trazem a formalização de Wallas (1926) em sua obra "A arte do pensamento", em que normatiza o processo de chegar a uma nova generalização, invenção ou expressão poética de uma nova ideia com um modelo de processos criativos dividido em quatro etapas: preparação, incubação, iluminação e verificação. 
A fase de preparação, segundo Lubart (2007, p. 94), "necessita de uma análise preliminar a fim de definir e de colocar o problema. Ela requer um trabalho consciente e demanda educação, capacidade analítica e conhecimentos sobre o problema”. Durante a fase de incubação, não há trabalho consciente sobre o problema:

A fase de iluminação aparece quando a ideia se torna consciente. Lubart (2007, p. 94) diz que "a iluminação pode se definir por um flash, uma iluminação súbita". É uma fase perturbada por acontecimentos externos, ou quando se tenta precipitar a emergência de ideias.

A fase de verificação, também chamada de trabalho consciente, é quando se necessita avaliar, redefinir e desenvolver a ideia (LUBART, 2007). Wallas (1926 apud LUBART, 2007) observou que, ao longo do processo de resolução criativa do problema, pode-se voltar às primeiras etapas. "Se por exemplo, uma ideia mostrou as imperfeições no momento da verificação, uma outra ideia poderia incubar para resolver essa dificuldade" (LUBART, 2007, p. 95). E, ainda, da mesma maneira, "as fases poderiam se sobrepor, por exemplo, quando uma pessoa procura, às vezes, em uma etapa de preparação, por um aspecto do problema e na fase de incubação por um outro aspecto do problema" (LUBART, 2007, p. 95). O modelo em quatro etapas, ou uma de suas variantes, auxilia muitas pesquisas, afirma Lubart (2007).

Em síntese, começa-se pela apresentação da tarefa - estabelecimento da tarefa ou problema e levantamento das dificuldades- para então passar às etapas do processo criativo, conforme Lubart (2007):

1. Preparação: coleta de informação; análise inicial; trabalho consciente.

2. Incubação: descanso; jogo associativo inconsciente; esquecimento dos detalhes.

3. Iluminação: experiência "Eureka"; emergência da ideia.

4. Verificação: exame crítico da ideia; conclusão dos detalhes.

De acordo com Ostrower (2014), a criatividade está vinculada ao trabalho das pessoas, isto é, os processos criativos surgem dentro dos processos de trabalho, e este fazer intencional da pessoa é um fazer significativo. Para a autora, os processos criativos são processos construtivos globais. "Envolvem a personalidade toda, o modo de a pessoa diferenciar-se dentro de si, de ordenar e relacionar-se em si e de relacionar-se com os outros. Criar é tanto estruturar quanto comunicar-se, é integrar significados e é transmiti-los" (OSTROWER, 2014, p.142143).

A Modelagem na Educação, proposta por Biembengut (2016) considera os processos criativos e a criatividade dos estudantes ao elaborarem modelos, sejam estes matemáticos ou 
não, e também apresenta fases a serem seguidas no processo de modelar. Para Biembengut (2014), a modelagem é um processo de pesquisa, cuja essência "emerge na mente de uma pessoa quando alguma dúvida genuína ou circunstância instigam-na a encontrar uma melhor forma para alcançar uma solução, descobrir um meio para compreender, solucionar, alterar, ou ainda, criar ou aprimorar algo" (BIEMBENGUT, 2014, p. 21).

Para Bassanezi (2010, p.45), "trata-se de um processo dinâmico de busca de modelos adequados, que sirvam de protótipos de alguma entidade". Para o autor, modelo matemático consiste em um conjunto de relações matemáticas e símbolos que, de alguma maneira, representam o objeto estudado. Ele afirma que esses modelos matemáticos podem ser formulados conforme a natureza dos fenômenos ou situações analisadas e classificadas de acordo com o tipo de matemática utilizada.

Biembengut (2014, 2016), com base em Kant (1980) e Maturana e Varela (2007), denominou os três estágios do processo cognitivos (etapas de modelagem na educação), a saber: percepção e apreensão; compreensão e explicitação; e significação e expressão.

Percepção e apreensão - processo que consiste em receber, identificar e classificar informações. É a primeira fonte de conhecimento necessária para que se possa fazer uma descrição do meio, uma decodificação e representação. Posteriormente, a percepção e apreensão têm relações com o pensamento, com a resolução de problemas e com os processos de decisão das pessoas. É o momento em que há a escolha do tema, no processo de modelar, e familiarização com o assunto.

Compreensão e explicitação - Compreender é entender e expressar uma sensação de forma intuitiva. Ao se deparar com uma nova percepção, a mente busca explicar e relacionar com algo conhecido e, a partir disso, deduzir fenômenos derivados. Corresponde à formulação e resolução do problema e modelo.

Significação e expressão - Depois de compreendidas e explicitadas as informações ou percepções, há uma busca para representá-las ou traduzi-las. Estas representações são feitas por meio de símbolos ou modelos, e podem ser mentais ou físicos. Estes modelos são validados e avaliados nesta etapa, verificando-se a necessidade de se voltar às fases anteriores do processo, caso necessário.

De acordo com Madruga e Lima (2019, p. 254)

A utilização dos princípios de modelagem mostra-se como uma possibilidade, buscando a formação de sujeitos capazes e sensíveis na identificação e na solução das questões atuais. Além disso, ambientes que proporcionem esses atributos são potenciais espaços para o desenvolvimento da criatividade. Garantir esses espaços em ambientes formais de ensino deve ser tarefa a ser cumprida na composição curricular. 
Nesse sentido, considera-se que a modelagem pode ser um caminho para o ensino e aprendizagem de matemática desde na Educação Básica e no Ensino Superior, potencializando o desenvolvimento da criatividade nos estudantes.

\section{Procedimentos metodológicos}

Este artigo apresenta recorte de uma pesquisa qualitativa, de acordo com Bogdan e Biklen (2010), pois contempla características como: o ambiente natural é a fonte dos dados e o investigador é o instrumento principal; é descritiva; há interesse pelo processo; a análise de dados ocorre de forma indutiva; há preocupação com o significado. A pesquisa da qual originou este artigo abarcou um quantitativo de 10 profissionais de diferentes áreas, neste artigo é apresentado apenas um caso: a arquiteta.

Para atingir o objetivo proposto, utilizou-se o mapeamento na pesquisa educacional como princípio metodológico, conforme Biembengut (2008). O qual busca mostrar um panorama geral dos dados começando pela identificação, levantamento, classificação, organização e posterior análise desses dados, possibilitando a formação de uma imagem da realidade. Neste artigo dividiu-se o mapeamento em duas etapas: apreensão dos dados, oriundos das narrativas da profissional colaboradora da pesquisa; e significação desses dados por meio da interpretação, classificação e análise das informações obtidas.

$\mathrm{Na}$ apreensão ocorreu inicialmente a compreensão das bases teóricas que sustentam a pesquisa, qual sejam: Modelagem (matemática) na Educação e Processos Criativos; o reconhecimento da profissional colaboradora (arquiteta), assim como de seu trabalho por meio de entrevista narrativa e observações in loco. A arquiteta que concedeu os dados para esta pesquisa atua prioritariamente na criação e desenvolvimento de projetos de edificações, vinculada à uma Prefeitura Municipal de uma cidade do sul do Brasil. No momento da entrevista estava especificamente trabalhando na Secretaria de Educação do município, na construção, ampliação e reforma de escolas para atendimentos de estudantes da Educação Infantil e Educação Básica, particularmente Ensino Fundamental.

A entrevista por meio de narrativa foi realizada no local de trabalho da arquiteta, no horário de intervalo de suas atividades e durou aproximadamente 30 minutos. A opção pela narrativa deu-se pelo fato de contar história é dar sentido a percursos e experiências. Para Clandinin e Connelly (2000), a narrativa é uma boa forma de compreender e estudar a experiência. E o pensamento 'narrativo' é uma forma de expressar a experiência, o viver, o fazer, maneira de escrever e pensar sobre a mesma. 
As observações realizadas na sala onde a arquiteta trabalha foi outro tipo de coleta de dados, a profissional mostrou projetos de edificações no qual estava trabalhando naquele momento, entre outros documentos. Biembengut (2008) afirma que a observação deve ser suficientemente acurada para ser possível ampliar e qualificar os elementos pesquisados.

A significação dos dados deu-se após a coleta, foi o momento da análise das narrativas e do diário de campo (produzido no decorrer da pesquisa e principalmente no decurso das observações). Nesta etapa procurou-se perceber e compreender a estrutura e os traços dos entes ou fenômenos da pesquisa, na busca por interpretá-los e avaliá-los criteriosamente. Biembengut (2008) afirma que explicitar as significações dos dados coletados necessita de percepção e compreensão dos mesmos, bem como de interpretação e avaliação do contexto e das pessoas envolvidas e, especialmente, de um julgamento do que é relevante e seu de grau de relevância.

Para Biembengut (2008), a descrição e a compreensão são realizadas durante o percurso da pesquisa, e a interpretação e avaliação dos fenômenos ou entes de uma pesquisa dependem do conhecimento do pesquisador sobre a teoria que sustenta o tema em questão, bem como da proposta de outro olhar sobre a teoria. Para efetuar a análise dos dados dessa pesquisa, apreciaram-se e avaliaram-se as narrativas da profissional colaboradora, dividindo-as conforme sua relevância, ou seja, categorizando e identificando os principais elementos, tanto constantes como variáveis.

\section{Discussão dos resultados}

Nesta etapa faz-se a análise dos dados empíricos coletados com a arquiteta que colaborou com esta pesquisa. As categorias de análise emergiram das observações e das narrativas concedidas pela entrevistada. A análise por meio das observações in loco permitiu à pesquisadora identificar as categorias no trabalho da arquiteta, pois converge para um processo de criação no qual há uma intencionalidade para, posteriormente, se planejar ou projetar o que será feito, seguido por um processo de criação e avaliação do objeto ou modelo criado, ou seja, do produto. Dessa forma foi possível determinar as seguintes categorias, que serão explicitadas, explicadas e analisadas na sequência: intenção, projeção, criação e produto.

\subsection{Intenção}

É aquilo que se pretende fazer, uma ideia, um plano ou aquilo que uma pessoa espera que aconteça (MADRUGA, 2016). De acordo com Japiassú e Marcondes (2011), intenção é 
um propósito, sentido, direção, finalidade ou objetivo que determina certa ação. Para que a produção de algo ocorra, em qualquer setor profissional, deve-se ter a intenção, um propósito.

No que se refere ao primeiro estágio de modelagem, conforme Biembengut (2014), percepção e apreensão, o intuito é identificar, entender o que deve ser feito no processo de modelação/criação. Nesta primeira categoria, considera-se a priori que para realização de um trabalho, em qualquer ramo profissional, há intenção, ou seja, é necessária uma identificação do que será feito: primeira ação da pessoa. Este fato torna-se evidente no excerto: “[...] começa com a solicitação de alguém, pode ser de um cliente, pode ser da secretaria de educação, pode ser das diretoras de escola, ou de um cliente particular". Com essa fala inicial da arquiteta, percebe-se que seu trabalho se inicia a partir de uma solicitação, ou seja, uma intenção.

No momento da coleta de dados a arquiteta fazia parte de uma equipe que tinha sob responsabilidade dois Ginásios Municipais, 18 Centros Municipais de Educação Básica (CMEB), que são escolas de Ensino Fundamental, cinco Escolas Municipais de Educação Infantil (EMEI) e ainda uma EMEI que estava sendo construída. O trabalho nas escolas e ginásios em funcionamento centra-se em reformas, modificações e ampliações para melhores condições de atendimento à comunidade escolar. Para cada caso, são necessários projetos que possibilitem cumprir tais demandas.

Em suas narrativas, diz que percebe o que deverá apresentar quando recebe uma solicitação para que desenvolva determinado projeto, na maioria dos casos é um problema que uma pessoa - cliente - enfrenta. Como a arquiteta trabalha com edificações, as solicitações a ela dirigidas normalmente são de construções e/ou reformas de prédios, tanto públicos (função atual) quanto particulares.

Seu trabalho parte da demanda de algum cliente: "começa com a solicitação de alguém”. Esta requisição pode vir de uma empresa, um órgão público ou um cliente em particular, afirma a entrevistada. Conforme suas narrativas: "Daí chegam pra mim e dizem - 'olha, eu tô com um problema que eu tô precisando resolver': 'eu tô precisando ampliar a minha casa para determinada função', ou então, 'a quadra do colégio não comporta tantos alunos sentados a gente precisa ampliar para uma maior arquibancada'”. Essas afirmações demonstram que esse 'problema', ou seja, questão social que depende de algum tipo de esforço para ser solucionado, pode ser uma aspiração de algum cliente por melhores condições em termos de estrutura prédios, decorrente de algo que não está lhe satisfazendo plenamente, ou apenas um desejo de uma nova construção.

A partir do problema apresentado, ou seja, da dificuldade em atingir determinado objetivo, da intenção do cliente, a arquiteta cria um modelo de edificação, seja construção nova 
ou reforma que satisfaça o cliente: "sempre uma solicitação vinda de algum problema que alguém me passa".

Dessa forma, conforme as narrativas da entrevistada, pode-se perceber que inicialmente há uma interação com o assunto que perpassa pela percepção resultando em uma intenção em realizar determinado trabalho, em criar determinado produto, ou seja, há um reconhecimento da situação. Pode-se dizer que o primeiro estágio do trabalho da entrevistada vem ao encontro da primeira etapa de modelagem. Segundo Bassanezi (2015, p. 16), “o início de uma modelagem se faz com a escolha de temas".

No que diz respeito à escolha do tema para o trabalho de modelagem matemática no ensino, Biembengut (2007, p. 40) salienta que:

\begin{abstract}
A escolha do tema não é simples. A ideia de cada aluno escolher um assunto de interesse nem sempre proporciona os resultados esperados. Se os dados sobre o tema escolhido forem tão simples que não acrescentam qualquer conhecimento no que diz respeito à matemática, ou ainda, se não forem fáceis de obter esses dados, pode gerar desmotivação e desinteresse pelo trabalho. Neste caso, a orientação do professor na etapa inicial - escolha do tema - é essencial para evitar que isso ocorra no meio do processo.
\end{abstract}

Estas considerações de Biembengut (2007) para o ensino podem ser transpostas para o trabalho da entrevistada. Cada profissional, assim como o professor, deve orientar para que o tema, a ideia escolhida, possa gerar um modelo satisfatório.

Pelo exposto, a intenção, ou escolha do tema, ideia ou objetivo é fundamental para que se tenha uma ação, uma criação, seja em qualquer ramo profissional, seja no ensino, por meio da modelagem matemática. Assim, pode-se dizer que na primeira ação da arquiteta há uma percepção sobre o assunto (BIEMBENGUT, 2016), e uma análise preliminar do problema, o que corresponde a uma preparação, denominada por Lubart (2007).

\title{
4.2 Projeção
}

É a ação ou efeito de projetar, ou seja, formar um projeto. Para Madruga (2016), a projeção é considera a etapa anterior à execução, é uma fase de planejamento, de apropriação e 'imaginação' do produto que será exposto e validado pela própria pessoa que cria, bem como pelas demais envolvidas ou não no processo.

Conforme a análise, a projeção é uma mescla do processo de modelar: a apreensão ( $1^{\mathrm{a}}$ etapa) e compreensão ( $2^{\mathrm{a}}$ etapa), ambas prescritas por Biembengut (2016). A projeção caracteriza-se pelas ações de busca por subsídios, levantamento de informações, e imaginação do produto. A entrevistada afirmou em sua narrativa que busca subsídios para sua produção, o 
que pode ser verificado no seguinte excerto: “[...] se faz um levantamento das necessidades dessa pessoa que está apresentando o problema”.

A entrevistada diz que, após a solicitação do cliente, passa-se aos levantamentos de dados acerca da necessidade deste cliente, ou seja, as buscas são para responder às seguintes questões: Quantos são? Para que servem? Quem vai beneficiar? Quais são as necessidades? Após essas questões serem respondidas, e normalmente o cliente mesmo é quem as responde, passa-se então ao levantamento físico: Onde vai ser implantado? Tipo e características do terreno? Se há e o tipo de edificações no entorno? Ambiente urbano ou rural? Incidência de sol? As demais observações de dados acerca de terreno, clima e vizinhança do local da construção constituem a fase de levantamentos realizada pela arquiteta.

Conforme suas palavras: "primeira coisa são os levantamentos, a gente faz um levantamento das necessidades dessa pessoa que está apresentando o problema: Quantos são? Pra que servem? Quem vai beneficiar? Quais são as necessidades que eles podem nos comentar falando. Tudo isso é anotado e gravado como a primeira parte dos levantamentos". E prossegue suas narrativas: “depois tem o levantamento físico, aonde que isso vai ser implantado: ah... é um terreno plano, é um terreno em aclive, num morro, numa encosta, tem pedra, não tem, tem edificações de entorno que normalmente é muito importante pra nós, os vizinhos são em que alturas, num ambiente urbano tu tens variadas alturas de edificações, às vezes tem uma casa, às vezes tem um prédio; a incidência do sol que é muito importante considerar também, sol, vento, chuva... então são os levantamentos físicos".

Para Burak e Klüber (2011), os levantamentos também são importantes em atividades de modelagem: “[...] entendemos, pois, que para conhecer de forma mais ampla, mais detalhada algum objeto ou alguma situação, é necessário organizar, saber o que e como enunciar questões que produzam respostas às questões" (BURAK; KLÜBER, 2011, p.49).

A entrevistada ainda fala sobre outro tipo de levantamento, de acordo com suas narrativas: "levantamento de referências, que a gente usa muito, por exemplo, o teu cliente pede um negócio e tu vai buscar referências de coisas já executadas, que tu acredita que se assemelham com aquilo que o teu cliente tá te pedindo". A arquiteta diz que este tipo de levantamento facilita tanto a profissional, para desenvolvimento de seu projeto, como o cliente, que pode visualizar uma obra similar e verificar como possivelmente ficará sua solicitação: “ele enxergando algumas coisas parecidas com o que eu acho que vai servir para ele, ele vai conseguir me passar melhor se é aquilo ou não. Aí eu não vou precisar entrar na fase de projeto com a coisa errada, com o pé errado sabe... eu não vou começar errado". 
Para Ostrower (2014, p.58),

As disposições, imagens da percepção, compõem-se, a rigor, em grande parte de valores culturais. Constituem-se em ordenações 'características' e passam a ser normativas, qualificando a maneira por que novas situações serão vivenciadas pelo indivíduo. Orientam o seu pensar e imaginar. Formam imagens referenciais que funcionam ao mesmo tempo como uma espécie de prisma para enfocar os fenômenos e como medida de avaliação.

A entrevistada menciona que é necessário entender o que o cliente quer, e muitas vezes essas imagens referenciais auxiliam neste processo. Afirma que muitas vezes pretende um tipo de projeto e o cliente outro: "estou querendo um projeto super funcional, minimalista sem grandes decorações e ele não, ele tá querendo em vez de um quarto sem nada de decoração, ele tá querendo um quarto super rebuscado, todo cheio de frufrus, então é nessas imagens referenciais que tu mostra para o teu cliente, que vocês vão chegar numa linguagem que os dois entendam".

E justifica: "a fase de projeto é muito demorada, e seguidamente acontece de tu começar o projeto de um jeito, chegar lá apresentar para ele e quando tu vê, não era aquela linguagem estética que ele tava querendo". Por estes motivos, os levantamentos e a comunicação entre cliente e profissional são fundamentais. "Quanto maior o tempo disponível para [...] perceberem e apreenderem o tema escolhido, melhor será o resultado" (BIEMBENGUT, 2014, p. 35). Esta etapa, onde se buscam subsídios para as ideias emergirem, correspondem às fases de preparação e incubação (LUBART, 2007) e às fases de apreensão e compreensão (BIEMBENGUT, 2016).

\subsection{Criação}

É o ato de criar, ou seja, poder dar forma a algo novo. "A idéia de criação está ligada à de autor, de uma dependência da obra criada relativamente a seu criador, de uma novidade, que pode ser absoluta ou relativa" (JAPIASSÚ; MARCONDES, 2011 p.45).

Assim como a etapa anterior - 'projeção' -, esta fase também é organizada em dois momentos: elaboração dos primeiros esboços (modelos) - explicitação (BIEMBENGUT, 2016); e construção efetiva do produto que cada profissional se propõe a fazer - significação (BIEMBENGUT, 2016).

A entrevistada comenta que costuma fazer muitos esboços antes de desenhar o projeto final a ser apresentado à cliente: "faço bilhões de esboços, desde esboços que eu mesmo faço e eu mesmo renego eles, porque não ficaram bons, mas eu preciso desenhar muito pra chegar a uma solução. E desde coisas que eu acho ok, ficou ótimo, mas aí eu apresento para o cliente e não era bem aquilo que ele estava pensando, então aí eu volto a fazer novos esboços”. Em seus 
processos de criação, a arquiteta é considerada uma pessoa criativa, pois, conforme definição de Gardner (2001), um indivíduo criativo é quem resolve regularmente problemas ou inventa produtos em um âmbito, e cujo trabalho é considerado inovador e aceitável por membros reconhecidos em determinado campo.

A arquiteta diz que, para resolver de forma satisfatória o problema do cliente, precisa fazer um esboço que realmente o agrade, sendo necessário entender o que a pessoa imagina para aquele projeto, e enfatiza que a comunicação com o cliente é de extrema importância no processo. De acordo com suas narrativas: "tentar captar o que o teu cliente quer em termos tanto de estética, quanto de funcionalidade. [...] Entender o que ele está querendo. Isso é uma parte bem complicada, porque às vezes tu imagina, tu chega numa solução perfeita, e não é aquilo que ele está imaginando... Ou por falta de comunicação, falta mesmo, ou por falha de comunicação".

A arquiteta busca resolver um problema solicitado por um cliente. A criação do projeto é elaborada após a projeção, ou seja, após os levantamentos realizados e aprovação do cliente. A partir disso, começa a fase de construção do projeto: "daí vai para parte de criação, que tu pega esses levantamentos e tenta achar uma solução que se encaixe da melhor forma".

A entrevistada afirma que sua criação acontece de maneira parcial, pois precisa adaptar suas ideias às condições do entorno: "normalmente o processo de criação para nós ele é um processo parcial de criação, porque nunca tu tem um terreno isolado que tu possa fazer qualquer coisa e tudo vai se encaixar, então nosso processo de criação está vinculado a se encaixar da melhor forma em determinadas condições, ele sempre está limitado e eu particularmente, sempre tento encaixar essa edificação que vai solucionar o problema dos meus clientes, seja eles quais forem, da forma que [...] mais se adéque ao entorno".

A arquiteta enfatiza que suas criações não são exatamente de acordo com ideias e que dependem de fatores externos: "esse processo de criação é sempre limitado aos condicionantes que o local e que o teu cliente te fornece". Comenta que muitas vezes seu trabalho termina quando o projeto é entregue ao cliente, outras vezes há um acompanhamento da obra por parte deste profissional, dependendo do tipo de contrato: "depende do tipo de contrato. Se for completo, aí eu vou até o final da obra mesmo. Eu acompanho a obra”.

Conforme as narrativas, esta fase de 'criação' é composta pelas ações de produção de esboços e de produtos (modelos) que os entrevistados irão apresentar para apreciação das pessoas, sejam clientes ou o público de uma maneira geral. Pode-se dizer que nesta etapa houve a formulação e resolução do problema, etapa da modelagem matemática proposta por Biembengut (2007) e Bassanezi (2010). Conforme Biembengut (2007), esta etapa, 
especialmente importante na modelagem matemática, consiste na classificação das informações coletadas na fase anterior, na identificação dos fatos envolvidos, na formulação do modelo.

A formulação do problema baseia-se na elaboração dos primeiros esboços, enquanto que a execução é a resolução do problema (modelo) (BASSANEZI, 2010). Dessa forma, esta terceira fase de 'criação', ou seja, uma mescla das fases de 'explicitação' e 'significação', conforme Biembengut (2016), implica formular e resolver o problema, isto é, aplicar o modelo. De acordo com Lubart (2007) seria uma etapa de emergência de ideias, ou seja, de iluminação.

\subsection{Produto}

É o resultado de uma produção ou, no caso, da fase anterior de 'criação'. Nesta etapa, não necessariamente a última, mas apenas uma do processo de 'engrenagem', ocorre a interpretação da solução e validação e avaliação do modelo (produto) (BASSANEZI, 2010). É quando ocorre a expressão do que foi criado, quando o modelo é validado e avaliado por todas as pessoas (BIEMBENGUT, 2016). Essa verificação (LUBART, 2007) avalia-se o produto foi satisfatório, esta etapa é considerada a final. Se for insatisfatório, retorna-se à etapa anterior ‘criação' - ou até mesmo às etapas de 'projeção’ e ‘intenção’, conforme necessidade.

Uma vez traduzidos e representados os dados por meio de um modelo, é preciso saber se faz sentido e se é válido. Além disso, é preciso avaliar em que medida o modelo contribui para a solução da situação-problema e, por fim, verificar, sistematicamente, a valia do modelo na produção ou na transformação de alguma coisa: objeto, técnica, tecnologia, teoria (BIEMBENGUT, 2007).

Dessa forma, a etapa da expressão do produto é demarcada pela interpretação, validação e avaliação do modelo, ou seja, do produto criado pela profissional entrevistada. A avaliação dos projetos criados pela arquiteta é feita pelo cliente que contratou seus serviços e pela própria profissional. A entrevistada diz que, no caso dos projetos criados por ela, verifica se as obras estão sendo construídas conforme suas ideias. Sobre sua avaliação diz que a faz: "o tempo inteiro! Enquanto eu estou passando... tem obras que tu faz longe aí tu conclui tu nunca mais vai ver ela, mas normalmente não, normalmente as tuas obras são meio que no teu entorno assim, então enquanto tu enxerga ela, eu avalio o tempo inteiro. Enquanto eu tô enxergando a obra eu tô avaliando".

A arquiteta explica a diferença entre as solicitações dos clientes, pode ser apenas para a profissional criar o projeto, pode ser para acompanhar a obra projetada, ou ainda para administrar a obra: "no contrato anterior está previsto, se é só para projeto, entrega-se o projeto e nem toma conhecimento da obra [...] se é para projeto e acompanhamento de obra, se é para 
projeto e administração de obra, tem esses três tipos". E explica os dois últimos: “acompanhamento tu vai lá e só vai conferir se os caras estão fazendo igual ao teu projeto, ou solucionando alguma coisinha que surgiu de ordem estética durante a obra. [...] Administração significa que tudo que envolve a obra é tu quem decide, tu que vai pagar o pessoal, tu que vai contratar gente para isso, então é bem mais desgastante, bem mais trabalhoso".

A profissional menciona sobre a fase da obra e a necessidade de adaptações e mudanças durante o processo, o que indica uma avaliação de acompanhamento. "A fase de obra é complicada, sempre acontece várias coisas durante a obra que tu não tinha previsto, por mais que tu esmiúce muito no projeto, sempre vai ter alguma coisinha que tu vai ter que decidir na hora [...] quando dá faço mudanças durante o processo. É um processo com pessoas, então tu não consegue fazer as coisas sozinha”. E prossegue falando sobre as necessidades de mudanças durante o percurso da obra: "normalmente a obra não fica exatamente como tu gostaria. [...] Isso é um processo que acontece muito, ou porque durante a obra o cliente também quis mudar coisas. [...] Então tem diversos fatores que podem influenciar nesse processo".

No que se refere ao produto final, à construção e à sua avaliação e acompanhamento, a arquiteta comenta: "tem obras que são maravilhosas que tu olha no final e ficou exatamente como eu imaginava. [...] depende das pessoas envolvidas".

Dessa forma, 'produto' é uma 'expressão' que ocorre depois de compreendidas, explicitadas e verificadas as informações ou percepções. É uma busca por representá-las ou traduzi-las por meio de símbolos ou modelos. São as representações que a pessoa consegue expressar ou produzir externamente por meio de suas produções artísticas.

Dessa forma, sintetizou-se no Quadro 1 a relação entre as etapas propostas nesta pesquisa, as fases da modelagem (BASSANEZI, 2010; BIEMBENGUT, 2016) e as etapas dos processos criativos (LUBART, 2007).

Quadro 1 - Categorias de análise, etapas de modelagem e processos criativos.

\begin{tabular}{|c|c|c|c|c|}
\hline \multicolumn{2}{|c|}{ MODELAGEM } & $\begin{array}{l}\text { CATEGORIAS } \\
\text { DE ANÁLISE }\end{array}$ & $\begin{array}{l}\text { PROCESSOS } \\
\text { CRIATIVOS }\end{array}$ & $\begin{array}{l}\text { TRABALHO DA } \\
\text { ARQUITETA }\end{array}$ \\
\hline Reconhecimento & \multirow{2}{*}{$\begin{array}{l}\text { Percepção } \\
\text { e } \\
\text { Apreensão }\end{array}$} & INTENÇÃO & PREPARAÇÃO & Solicitação do cliente \\
\hline Familiarização & & \multirow[b]{2}{*}{ PROJEÇÃO } & \multirow[b]{2}{*}{ INCUBAÇÃO } & Levantamento de dados \\
\hline $\begin{array}{l}\text { Formulação do pro- } \\
\text { blema }\end{array}$ & \multirow{2}{*}{$\begin{array}{c}\text { Compreensão } \\
\text { e } \\
\text { Explicitação }\end{array}$} & & & $\begin{array}{c}\text { "Imaginação" da } \\
\text { melhor forma de } \\
\text { adequar }\end{array}$ \\
\hline Formulação do modelo & & \multirow[b]{2}{*}{ CRIAÇÃO } & \multirow[b]{2}{*}{ ILUMINAÇÃ̃O } & Esboços, desenhos \\
\hline Resolução do modelo & \multirow{2}{*}{$\begin{array}{l}\text { Significação } \\
\text { e } \\
\text { Expressão }\end{array}$} & & & Projeto \\
\hline Interpretação da solução & & PRODUTO & VERIEICACÃO & Avaliação \\
\hline
\end{tabular}

Fonte: Adaptado de Madruga (2016). 
A organização em categorias facilitou a análise no sentido de entender que a profissional entrevistada procura, inicialmente, perceber o entorno do tema ou problema que precisam resolver, reconhecendo o que existe sobre o assunto, e, na sequência, passa a apreender um referencial teórico que guie suas criações. Por meio da compreensão, conseguem projetar e esboçar o produto que passa por um processo de criação em que é significado e avaliado por meio da expressão das pessoas.

\section{Considerações finais}

Este artigo teve como objetivo compreender os procedimentos de trabalho de uma arquiteta, analisando-os comparativamente com as etapas da modelagem matemática. As entrevistas por meio de narrativas auxiliaram para o entendimento do trabalho desta profissional, e assim foi possível estabelecer as relações com a modelagem.

De acordo com a análise das narrativas, pode-se inferir que o trabalho da arquiteta perpassa etapas como: a) solicitação de outras pessoas (escolha do tema - percepção intenção); b) levantamento de dados (familiarização com o assunto - apreensão e compreensão - projeção); c) esboços - mentais e físicos - do que deve ser feito (formulação do problema e do modelo - criação - explicitação); d) projeto (validação e avaliação do modelo - produto significação e expressão).

Essas relações possibilitam a seguinte reflexão: se a arquiteta, assim como outros profissionais de diferentes ramos, utilizam etapas similares às de modelagem na perspectiva da Educação Matemática para realização de seus trabalhos, tal método pode ser eficaz também na Educação Básica, no ensino e aprendizagem de conteúdos de matemática, por exemplo.

Tal reflexão coaduna com as ideias de Madruga e Lima (2019), quando apresentam o "aprender com modelagem" como caminho promissor para contexto escolar. Para isso, "[...], é necessário que os professores, desenvolvam um trabalho de forma diferenciada, visando a resolução de problemas do cotidiano e que sejam relevantes para o grupo de estudantes, considerando suas realidades" (MADRUGA, 2017a, p. 102).

Como perspectiva de continuidade, tem-se a intenção de verificar na prática as potencialidades do "aprender com modelagem", elaborando e aplicando produtos educacionais que considerem os processos criativos e modelagem como métodos para a aprendizagem de matemática na Educação Básica, em diferentes contextos. 


\section{Referências}

ALENCAR, Eunice M. L. S. Criatividade. Brasília: Editora Universidade de Brasília, 1993.

BASSANEZI, Rodnei C. Ensino-aprendizagem com Modelagem Matemática. $3^{\mathrm{a}}$ ed. $2^{\mathrm{a}}$ reimpressão São Paulo: Contexto, 2010.

BASSANEZI, Rodnei C. Modelagem Matemática teoria e prática. São Paulo: Contexto, 2015.

BIEMBENGUT, Maria S. Mapeamento na Pesquisa Educacional. Rio de Janeiro: Editora Ciência Moderna, 2008.

BIEMBENGUT, Maria S. Modelagem matemática \& Implicações no Ensino e Aprendizagem de Matemática. $3^{\mathrm{a}}$ ed. Blumenau: Edifurb, 2007.

BIEMBENGUT, Maria S. Modelagem Matemática no Ensino Fundamental. Blumenau: Editora da FURB, 2014.

BIEMBENGUT, Maria S. Modelagem na Educação Matemática e na Ciência. São Paulo: Livraria da Física, 2016.

BOGDAN, Robert; BIKLEN, Sari. Investigação Qualitativa em Educação. Porto, Portugal: Editora Porto, 2010.

BRASIL. Ministério da Educação, Secretaria de Educação Básica. Base Nacional Comum Curricular. Brasília: 2018.

BURAK, Dionísio; KLÜBER, Tiago. Encaminhamentos didático-pedagógico no context de uma atividade de modelagem para a Educação Básica. In: ALMEIDA, Lourdes M. W.; ARAÚJO, Jussara L.; BISOGNIN, Eleni. Práticas de Modelagem Matemática na Educação Matemática. Londrina: Eduel, 2011, p. 44-64.

CLANDININ, Jean; CONNELLY, Michael. Narrative inquiry: experience and story in qual-itative research. São Francisco: Jossey-Bass, 2000.

GARDNER, Howard. Estructuras de la mente. Santafé de Bogotá, Colômbia: Fondo de Cultura Económica Ltda, 2001.

GARDNER, Howard. Os padrões dos criadores. In: BODEN, Margaret A. Dimensões da criatividade. Trad. Pedro Theobald. Porto Alegre: Editora Artes Médicas Sul, Ltda, 1999, p. 149-163.

JAPIASSÚ, Hilton.; MARCONDES, Danilo. Dicionário Básico de Filosofia. 16ª ed. Rio de Janeiro: Zahar, 2011.

KANT, Immanuel. Primeira Introdução à Crítica do Juízo. Trad. de Torres Filho, R. R. São Paulo: Abril Cultural, 1980. 
LUBART, Todd. Psicologia da criatividade. Trad. Márcia Conceição Machado Moraes. Porto Alegre: Artmed, 2007.

MADRUGA, Zulma E. F. Processos criativos e valorização da cultura: possibilidades de aprender com modelagem. Tese (Doutorado em Educação em Ciências e Matemática) Faculdade de Física. Pontifícia Universidade Católica do Rio Grande do Sul. Porto Alegre, RS, 2016.

MADRUGA, Zulma E. F. A modelagem (matemática) implícita nos fazeres de diferentes pesquisadores. Boletim do LABEM, v. 8, n. 14, jan/jun., 2017a.

MADRUGA, Zulma E. F. A modelagem (matemática) implícita nos fazeres de uma modista. Amazônia: Revista de Educação em Ciências e Matemática, v.13, n.28, jul-dez., 2017b.

MADRUGA, Zulma E. F.; LIMA, Valderez Marina R. Aprender com Modelagem: Relações entre Modelagem (Matemática) e Processos Criativos. ALEXANDRIA: R. Educ. Ci. Tec., v.12, n.2, p. 241-266, novembro, 2019.

MADRUGA, Zulma E. F.; LIMA, Valderez. M. R. Possibilidades de aprender com modelagem: uma investigação qualitativa. Revista Lusófona de Educação, v.40, n.40, agosto, 2018.

MADRUGA, Zulma E. F.; SCHELLER, Morgana. A Modelagem (matemática) implícita nos fazeres de uma designer de unhar artísticas e suas possíveis implicações para a educação.

Revista de Educação Matemática, São Paulo, v. 16, n. 21, p. 154-172, jan. /abr. 2019.

MATURANA, Humberto R.; VARELA, Francisco J. A árvore do conhecimento. Trad. Jonas Pereira dos Santos. 6a ed. Campinas: Editora Psy II, 2007.

OSTROWER, Fayga. Criatividade e processos de criação. 30ª ed. Petrópolis: Vozes, 2014. 